\title{
Physical, chemical, and biotic effects on arctic zooplankton communities and diversity
}

\author{
W. John O'Brien ${ }^{1}$
}

Department of Systematics and Ecology, University of Kansas, Lawrence, Kansas 66045

\section{Michael Barfield}

Department of Zoology, University of Florida, Gainesville, Florida 32611-8525

Neil D. Bettez ${ }^{2}$

Ecosystems Center, Marine Biological Laboratory, Woods Hole, Massachusetts 02543

Gretchen M. Gettel ${ }^{2}$ and Anne E. Hershey ${ }^{1}$

Department of Biological Sciences, University of Minnesota Duluth, Duluth, Minnesota 55812

\section{Michael E. McDonald}

U.S. EPA National Health and Environmental Effects Research Laboratory, Research Triangle Park, North Carolina 27711

\section{Michael C. Miller}

Department of Biological Sciences, University of Cincinnati, Cincinnati, Ohio 45221

\section{Howard Mooers}

Department of Geology, University of Minnesota Duluth, Duluth, Minnesota 55812

\section{John Pastor, Carl Richards, and Jeff Schuldt}

Natural Resources Research Institute, University of Minnesota Duluth, Duluth, Minnesota 55812

\begin{abstract}
We examined how physical and chemical factors and fish populations affected the presence and density of zooplankton species in 104 Alaskan arctic lakes. Five fish species and nine zooplankters were sampled from the lakes. Lake depth was related to the distribution of zooplankton in that smaller zooplankton species were found in deep lakes and large species in shallow lakes. Neither ionic strength nor chlorophyll was a major factor in zooplankton presence or absence. When fish were present, few, if any, very large zooplankton occurred together. However, the relationship between the presence and density of smaller-sized zooplankton species and the presence of specific species of fish was complex and did not fit anticipated patterns. The diversity of zooplankton in these arctic lakes was not related to chemistry or fish distribution, but species richness increased with increasing lake area and depth. For a few zooplankters (notably Holopedium gibberum), the fraction of lakes containing the zooplankter varied by region.
\end{abstract}

The study of freshwater zooplankton and zooplankton communities has a long and storied history (Forbes 1887).

\footnotetext{
${ }^{1}$ Corresponding author (w_obrien@uncg.edu). Present address: Department of Biology, University of North Carolina at Greensboro, Greensboro, NC 27402-6174.

${ }^{2}$ Present address: Department of Ecology and Evolutionary Biology, Cornell University, Ithaca, NY 14853.

\section{Acknowledgments}

We gratefully acknowledge the staff at Toolik Lake Field Station and the many undergraduate and graduate students who helped with the fieldwork for this study. IAB GIS Analysts Andrew Balser and Catherine $\mathrm{Xu}$ worked on the map of the Toolik area and geomorphic-trophic hypothesis lakes. We also thank Marion O'Brien and Amanda Floyd for their editorial assistance.

Funding was provided by the National Science Foundation
}

Early work focused on chemical and physical influences on zooplankton communities and biology (Hutchinson 1967). For example, Daphnia pulex is more tolerant of low oxygen than other species in the genus Daphnia and commonly occurs in ponds, which may develop low oxygen levels, especially during the winter. It was early recognized that $\mathrm{Hol}$ opedium gibberum only occurred in lakes with low $\mathrm{pH}$ and low levels of calcium (Hamilton 1958; Hutchinson 1967). Interest in the importance of $\mathrm{pH}$ in affecting zooplankton species and communities was revived with the identification of acid rain in the 1970s (Dillon et al. 1984; Doka et al. 1997).

through grants NSF/DEB-9509348 and 0080202 to A.E.H. and NSF/OPP-9400722 and 9615949, NSF/DEB9553064, and 9810222 to J.E.H. 
Interest in the physical factors that affect zooplankton was also an early phenomenon in limnology (Hutchinson 1967). It was well known that Diaphanosoma brachiurum was a warm-water species occurring only in the summer in temperate lakes, whereas Diaphnia longiremis was a cold-water species only occurring in the cool hypolimnion in the southern part of its range (Hutchinson 1967). Interest in the effect of lake morphometry followed the demonstration that lake productivity and fish production were greater in shallow than in deep lakes (Rawson 1952, 1955).

A more recent idea is that fish predation structures freshwater zooplankton communities (Hrbacek 1962; Brooks and Dodson 1965; O’Brien 1979; Northcote 1988; O'Brien et al. 1990). More recently, it has been claimed that not only do fish structure zooplankton communities but the strength or weakness of this predation may affect lower trophic levels through cascading trophic interactions (Shapiro 1980; Carpenter et al. 1985, 1987). For example, when planktivory is strong, zooplankton densities and biomass may be low, allowing phytoplankton to become abundant and even creating nuisance blooms (Shapiro and Wright 1984). Conversely, when planktivory is weak, zooplankton densities and biomass may be high and phytoplankton abundance low. Similar forces appear to be at work in other food webs (e.g., freshwater benthic [Brönmark et al. 1992] and rocky coastal marine [Paine 1966; Lotze and Worm 2001] food webs).

The arctic is a good region to study these effects of lake morphometry, water chemistry, fish presence, and community composition on zooplankton communities, because it is relatively pristine, with little regional anthropogenic pollution and natural fish communities unaltered by stocking. However, much previous work on arctic zooplankton community composition and structure has focused on either one lake or a small number of lakes (Hobbie 1980; O'Brien et al. 1997). Although there have been a number of surveys of arctic lake zooplankton, these surveys often only reported the presence or absence of zooplankton, with little other information (O'Brien et al. 1979).

In the present article, we present data describing 104 Alaskan arctic lakes, with an emphasis on zooplankton distribution and diversity, and addressing the following questions. (1) What is the relationship between the presence and diversity of zooplankton and lake morphometry? (2) What is the relationship between the presence and diversity of zooplankton and chemical parameters of the lakes? (3) What is the relationship between the presence, density, and diversity of zooplankton in these lakes and the presence of fish and the nature of the fish communities?

\section{Materials and methods}

Study area-The research was conducted in the piedmont region of the Brooks Mountains in the vicinity of the Toolik Lake Field Station (TLFS) $\left(68^{\circ} 38^{\prime} 00^{\prime \prime} \mathrm{N}, 148^{\circ} 36^{\prime} 15^{\prime \prime} \mathrm{W}\right), 248$ $\mathrm{km}$ south of Prudhoe Bay along the Dalton Highway (Fig. 1 ). The region is made up of gently rolling hills containing many hundreds of small lakes. The vegetation is primarily heath and tussock tundra (Walker and Walker 1996). The geology of the region is dominated by glacial advances and retreats emanating from the nearby Brooks Mountains. There have been four major glacial intervals in the area (Hamilton 1982 , 1986) with the two most recent, termed Itkillik I (40,000 yr BP) and Itkillik II $(25,000-11,000 \mathrm{yr}$ BP), resulting in a landscape mosaic of differently aged areas. Many lakes in the region are, consequently, kettle basins of small size, ranging from a few hectares to nearly 2,000 ha. The ice-free season is from mid-June through mid-September, and the lakes are dimictic, with epilimnetic temperatures reaching as high as $18^{\circ} \mathrm{C}$ during some summers. Dissolved oxygen is always high because of the extreme oligotrophic nature of these lakes (Miller et al. 1986; Whalen and Alexander 1986), with inorganic nutrients near detection limits, averaging $0.22 \mu \mathrm{mol} \mathrm{L}-1 \mathrm{NO}_{3}, 0.75 \mu \mathrm{mol} \mathrm{L}{ }^{-1} \mathrm{NH}_{4}$, and 0.8 $\mu \mathrm{mol} \mathrm{L}{ }^{-1} \mathrm{PO}_{4}$, and particulate phosphorus and nitrogen averaging $1.7 \mu \mathrm{mol} \mathrm{L}^{-1}$ and $31.3 \mu \mathrm{g} \mathrm{L}^{-1}$, respectively. However, Secchi depths are fairly shallow because of humic acids and are rarely $>5.5 \mathrm{~m}$ at midsummer, although they are sometimes deeper later in the summer.

Limnological and fish collection methods-One hundred and four lakes in the study area were visited at least once during summer stratification (late June to early August) in 1996-1999 (Fig. 1). This sampling schedule may have missed Diaptomus pribilofensis in a few lakes, because this species commonly appears during early July (Johnson pers. comm.). Because zooplankton densities vary through the summer, many of our analyses used presence/absence data, which should be less sensitive to date of sampling (as well as other sources of error, such as the nonrandom distribution of zooplankton). Some lakes were reached by walking from the TLFS or from the Dalton highway. In most cases, a helicopter dropped a crew and equipment near a series of lakes. A full suite of chemical and biological measurements was made on each lake, but methods are given only for those used in the present analysis. Conductivity was measured using a conductivity meter arrayed on a Hydrolab $\mathrm{H} 2 \mathrm{O}$ multiprobe, which was deployed from a small inflated raft anchored near the deepest point in the lake. Water for chlorophyll $a$ determinations was taken using a Van Dorn water bottle from $1 \mathrm{~m}$ below the surface, also from the anchored raft. While water was being collected, another raft was used to determine lake morphometry using a Furuno 150 sonar with a strip chart recorder. In the rare instances that the sonar was unavailable, maximum depth was measured using a hand-held dive sonar deployed from the stationary raft. Lake area was digitized using USGS maps.

For Chl $a$ determinations, lake water was filtered through a precombusted Whatman GF/C glass-fiber filter, then extracted in $90 \%$ acetone in a cool, dark place for $24 \mathrm{~h}$. Chl $a$ absorbance was measured on a Turner Designs 10-Au-005$\mathrm{CE}$ fluorometer. These techniques are described in greater detail at http://ecosystems.mbl.edu/ARC/data_doc/lakes/ 2001lakesprotocols.html.

Fish communities were surveyed by a variety of techniques, and gill nets were used as the major device for assessing the presence of pelagic species. Six fish species were distributed in the region: lake trout (Salvelinus namaycush), arctic char (Salvelinus alpinus), arctic grayling (Thymallus arcticus), round whitefish (Prosopium cylindraceum), slimy 


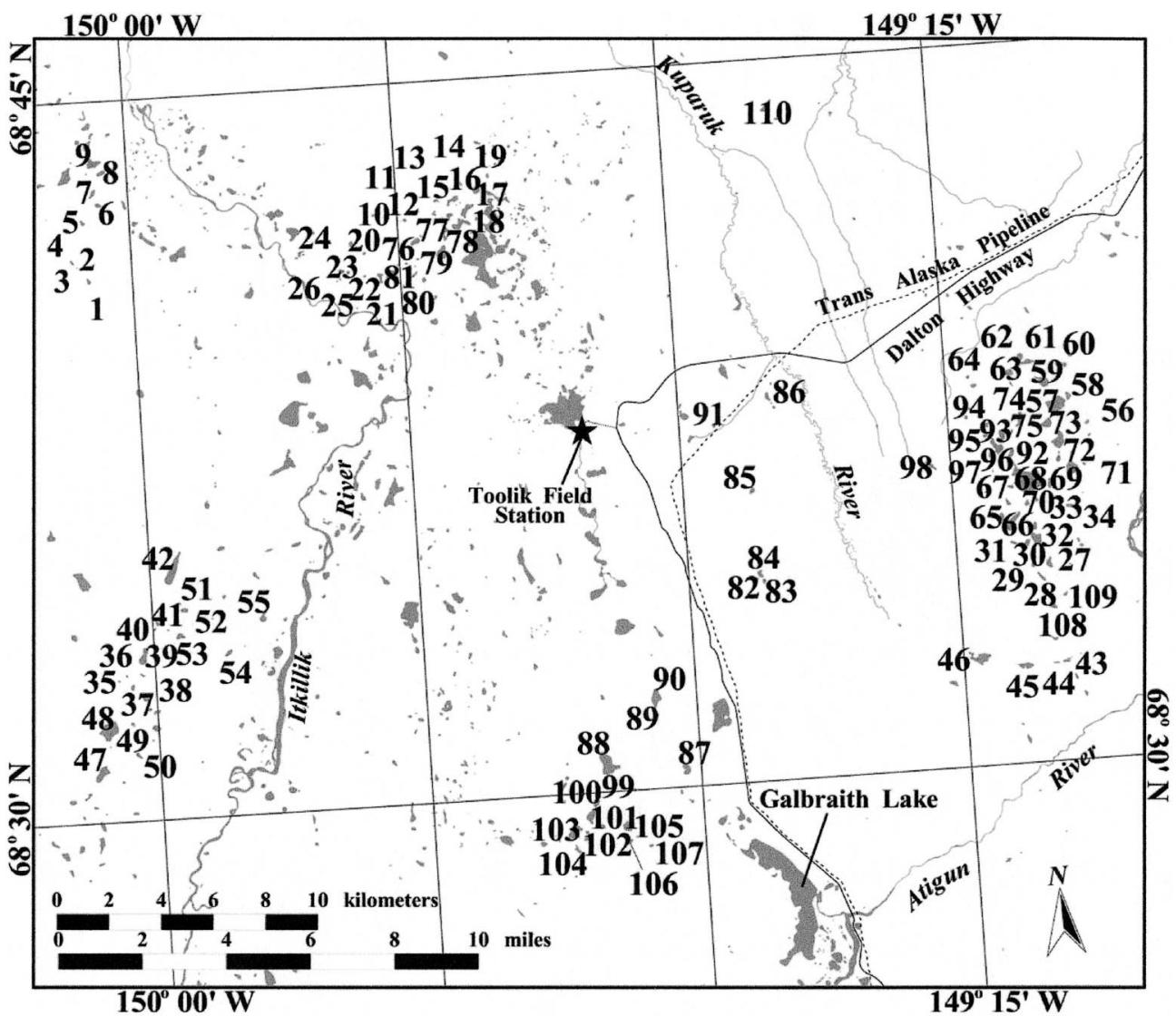

Fig. 1. The Toolik Lake region, showing the location of the geomorphic-trophic hypothesis lakes up through lake 110 .

sculpin (Cottus cognatus) and burbot (Lota lota). Burbot were not vulnerable to gill nets, angling, or trot lines and thus were not used in the analysis. The gill nets used had variable-sized mesh openings ranging $38-135 \mathrm{~mm}$ and were $26 \mathrm{~m}$ long and $1.4 \mathrm{~m}$ deep. The gill nets were deployed from an inflated raft running perpendicular to the shore, with the smallest mesh near shore. The nets were in the water for only a few hours, which was usually sufficient to determine the presence of fish species. Most fish were released. In lakes where fish were thought to be present (because of depth and outflow steepness) but were not captured during the gillnetting, angling was secondarily used to assess fish presence. Lakes that were too shallow to support fish were not resampled by angling. The presence of slimy sculpin was assessed using unbaited jar traps (McDonald et al. 1982) set for $\sim 24$ h. Traps were deployed from shore on the day before the full survey. Jar-trap surveys were supplemented with visual inspection from shore (sculpin could often be seen) and by using a minnow seine or dip net. There were few lakes in which we failed to catch fish where we expected them.

Zooplankton were collected using a $30-\mathrm{cm}$ diameter 335 $\mu \mathrm{m}$ mesh plankton net. This mesh size is small enough to capture all adult crustacean zooplankton, which are the only life stages that can be reliably identified as to species. The net was towed from the bottom of shallow lakes, and from $10 \mathrm{~m}$ in deeper lakes, to the surface. In very shallow lakes, several vertical tows were taken and pooled. Each sample had at least $6 \mathrm{~m}$ of total tow length, which would have sampled $>400$ liters, making it unlikely that a species with a density $>0.01$ individuals $\mathrm{L}^{-1}$ would be missed (assuming they were randomly distributed). The zooplankton were preserved with $100 \%$ ethanol and $4 \%$ formalin mixed $1: 1$ with the sample. Zooplankton were identified using the keys in Edmondson (1959) with an M-5 Wild dissecting microscope. The body lengths of Daphnia middendorffiana from five lakes containing fish (107 individuals) and five lakes without fish (218 individuals) were measured with an ocular micrometer in the dissecting microscope. Species richness (the number of species present) was used as a measure of zooplankton diversity.

Statistical methods-To investigate the co-occurrence of zooplankton species within lakes, the $G$ test was used (Williams's correction was used with all $G$ tests; Sokal and Rohlf 1981). To examine the correlations among densities of zooplankton species across lakes, a $\gamma$ test (similar to Kendall's $\tau$ test, with a correction for ties) based on ranks was done for all pairs of zooplankton. Zooplankton presence data were available for all lakes, but densities were measured in only 84 lakes (some lakes were too shallow to get an accurate quantitative sample). To examine the relationship between species occupancy (defined as the proportion of lakes in which the species occurred) and its average density in all 
lakes in which it was present, regression on the log-transformed local densities was used.

Logistical regression was used to test the effect of maximum lake depth, Chl $a$ concentration, and conductivity on the presence of each zooplankton species. Multiple logistical regression with lake depth and fish presence (any species) as predictors was also used to predict zooplankter presence. Lake depths were available for 87 lakes; data on chemical parameters were available for all lakes (except one for $\mathrm{Chl}$ a). Conductivity was negatively correlated $(-0.31)$ with $\mathrm{Chl}$ $a$. Because of this correlation, a separate set of regression analyses was done for conductivity and $\mathrm{Chl} a$. A $\gamma$ test was also used to test for any correlation between densities of each zooplankter and these two variables. Simple linear regression was used to test for relationships between the logarithm of species richness and physical and chemical parameters of the lakes. For lake area, this regression was done including all lakes and then repeated including only lakes with fish.

To examine the relationship between the presence of each zooplankton species and the presence of individual fish species and different fish communities, $G$ tests were used. First, for each zooplankter, the $G$ test was used to test for differences in its presence in lakes with fish compared with those without fish. Then the $G$ test was used to test for the independence of the presence of each zooplankter and each fish species. Finally, for all lakes with fish, the $G$ test was used to test whether the presence of each zooplankter depended on the fish community. For species present in more than half of the lakes (D. middendorffiana, Heterocope septentrionalis, D. pribilofensis, and Cyclops scutifer), the median densities were tested for dependence on the fish community (including lakes with no fish) using the Kruskal-Wallis test. This test was also used to test for differences in the median density of each zooplankter in the presence and absence of each fish species (except whitefish, which was present in few lakes).

A $G$ test was used to test for differences in the presence of each of the zooplankton species in the four major clusters of lakes (one each near Itigaknit and Galbraith Lakes, one east of the Kuparuk River, and one west of the Itkillik River) shown in Fig. 1 (lakes 1-9, 82-86, 91, and 110 were excluded). The average diversity of zooplankton was compared for different fish communities, and for lakes with and without fish, using analysis of variance.

\section{Results}

Description of lakes-The lakes of the Toolik region are relatively shallow and small. Their chemistry is quite variable. For example, the conductivity varies by a factor of 40 and chlorophyll by a factor of $\sim 1,000$ among these lakes. These major differences in chemistry are explained, at least in part, by differences in glacial history. There are some glacial maps of the region (Hamilton 1982) but no detailed glacial maps of the entire region covered by this survey. Therefore, it is not possible to characterize the probable age of all the lakes surveyed.

The shallowest lake visited was $<1 \mathrm{~m}$ deep, and the deepest was $37 \mathrm{~m}$ deep; the median depth was $9.1 \mathrm{~m}$. Lake areas ranged 0.1-79.7 ha, with a median and geometric mean of 3.1 ha. The lowest conductivity was $6.3 \mu \mathrm{S} \mathrm{cm}^{-1}$, and the highest conductivity was $256 \mu \mathrm{S} \mathrm{cm}^{-1}$. The lowest $\mathrm{Chl} a$ level was $0.0039 \mu \mathrm{g} \mathrm{L}^{-1}$, and the highest was $3.5 \mu \mathrm{g} \mathrm{L}^{-1}$.

As mentioned previously, six species of freshwater fish occur in the Toolik region of arctic Alaska, one of which, burbot, is quite difficult to sample. Given the five detectable fish species and the possibility of a lake having no fish, there are 32 possible fish combinations that could occur. Of these, 17 different fish communities, or combinations of fish species, including no fish, occurred in the 104 surveyed lakes. Six of these communities were found in only one lake each, and one community was present in only two lakes. Therefore, these seven communities (and eight lakes) were excluded from analyses by fish community because of inadequate sample size (leaving 96 lakes and 10 fish communities, each present in at least five lakes). The 10 communities analyzed were no fish present (25 lakes); grayling only (13); grayling and sculpin (9); grayling, sculpin, and whitefish (6); lake trout, grayling, and sculpin (12); sculpin only (5); lake trout and sculpin (6); lake trout, grayling, char, and sculpin (7); lake trout, char, and sculpin (5); and char and sculpin (8). Sculpin occurred alone and was present in every fish community except in those lakes that had only grayling. Grayling occurred alone and in four other communities. Lake trout did not occur alone but did occur in four communities. Whitefish occurred in only 1 of the 10 communities (the one with grayling, sculpin, and whitefish).

The lakes contained seven species of zooplankton within the size range of $0.4-4.0 \mathrm{~mm}$. These are listed in order of increasing body length as given in Edmondson (1959): Bosmina longirostris $(0.4-0.5 \mathrm{~mm}), D$. longiremis $(0.8-1.2$ $\mathrm{mm})$, D. pribilofensis $(1.0-1.8 \mathrm{~mm})$, C. scutifer (1.1-1.9 $\mathrm{mm}), H$. gibberum $(1.5-2.2 \mathrm{~mm})$, D. middendorffiana $(2.5-$ $3.0 \mathrm{~mm}$ ), and $H$. septentrionalis $(3.0-4.0 \mathrm{~mm})$. The littoral species Polyphemus pedunculus, although occasionally collected, was not included in the analysis because this species is a littoral-zone inhabitant, and we did not routinely sample the littoral zone for zooplankton. There were four species much larger than $4.0 \mathrm{~mm}$ : a phantom midge Chaoborus $\mathrm{cf}$. trivattatus (an invertebrate predator) and three herbivorous species: the fairy shrimps Brachionecta paludosa and Polyartemiella hazeni, and an amphipod of the genus Gammarus sp. Because fairy shrimp and amphipods are largebodied, herbivorous, and commonly occurred together, they are collectively referred to as "megaherbivores."

Analyses were conducted to determine the co-occurrence of particular species. The presence of $H$. septentrionalis was negatively related to the presence of both $D$. longiremis and B. longirostris (both species present in $>70 \%$ of lakes without Heterocope and $<30 \%$ of lakes with Heterocope), and the presence of $D$. longiremis was positively related to $B$. longirostris (each occurred in $\sim 42 \%$ of lakes, but they occurred together in $\sim 32 \%$; all three of these relationships were significant at $P<0.001$ ). The presence of $D$. longiremis was negatively related to Chaoborus (the former was present in $47 \%$ of lakes without Chaoborus and only $12 \%$ of lakes with Chaoborus; $P<0.01)$. There were also weaker relationships $(P<0.05)$ between the presence of $D$. longiremis and both $C$. scutifer (positive) and megaherbivores 


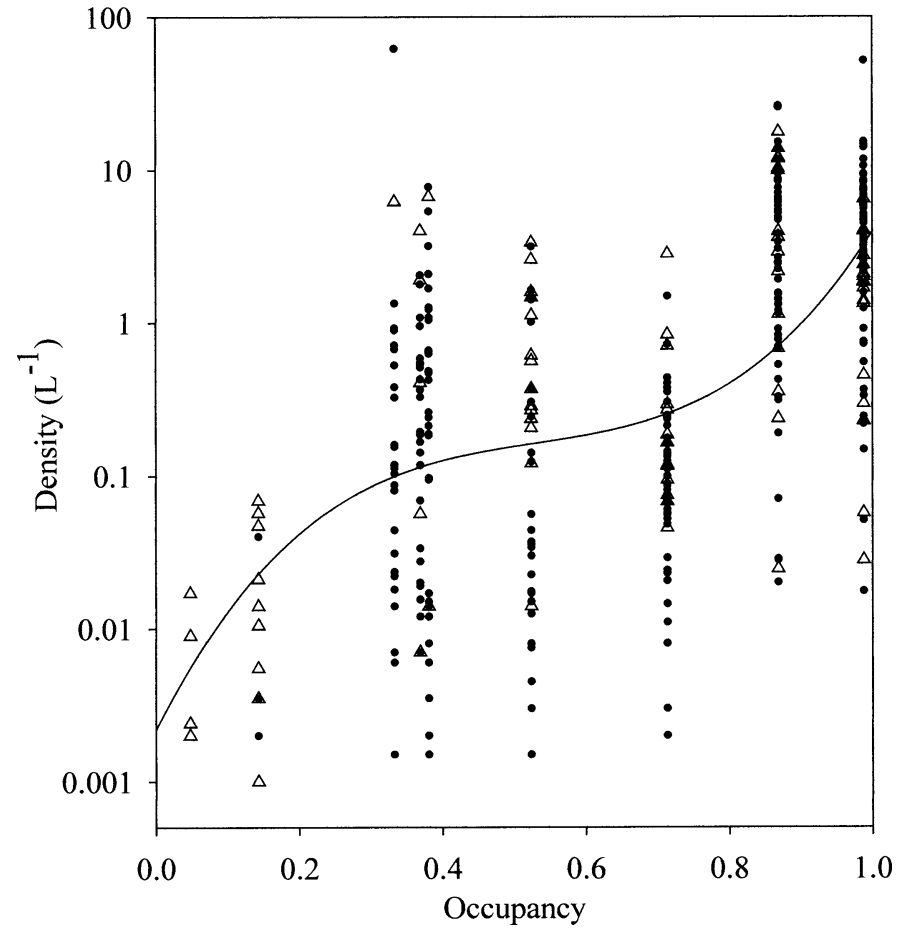

Fig. 2. The abundance (logarithm of density) of each zooplankter as a function of its range (occupancy - the fraction of lakes in which the species was present). Black circles represent lakes with fish; white triangles represent lakes without fish. The cubic regression line shown was calculated using all lakes $\left(r^{2}=35.7 \%, P<0.001\right)$. The zooplankters are, from left to right (low to high occupancy): megaherbivores (0.05), Chaoborus (0.14), B. longirostris (0.33), H. gibberum (0.37), D. longiremis (0.38), D. middendorffiana (0.52), $H$. septentrionalis $(0.71), D$. pribilofensis $(0.87)$, and C. scutifer (0.99).

(negative) and between $D$. middendorffiana and Chaoborus (positive; $P<0.05$ for all).

Similar results were found for correlations among densities of zooplankton species. The nonparametric $\gamma$ tests gave highly significant $(P<0.001)$ negative correlations between $H$. septentrionalis and both $D$. longiremis and B. longirostris. There were highly significant $(P<0.001)$ positive correlations of $D$. middendorffiana with Chaoborus and D. longiremis with $B$. longirostris.

Figure 2 shows the relationship between zooplankton abundance (density in lakes that contained the species) and range (here called occupancy, which is the proportion of lakes in which the species or group was found). White triangles represent lakes without fish. Two species (D. pribilofensis and C. scutifer, the rightmost two lines of points in Fig. 2) were present in almost all lakes and had relatively high densities. Two groups (megaherbivores and Chaoborus sp., to the left in the figure) were rare and had low densities. The other five species were more moderate on both scales. Linear regression was highly significant, but cubic regression is shown here because it gave a better fit and more normal residuals. The cubic regression line is an increasing function, with $r^{2}=35.7 \%$ and $P<0.001$. Therefore, these data indicate that the density of individual species of zooplankton

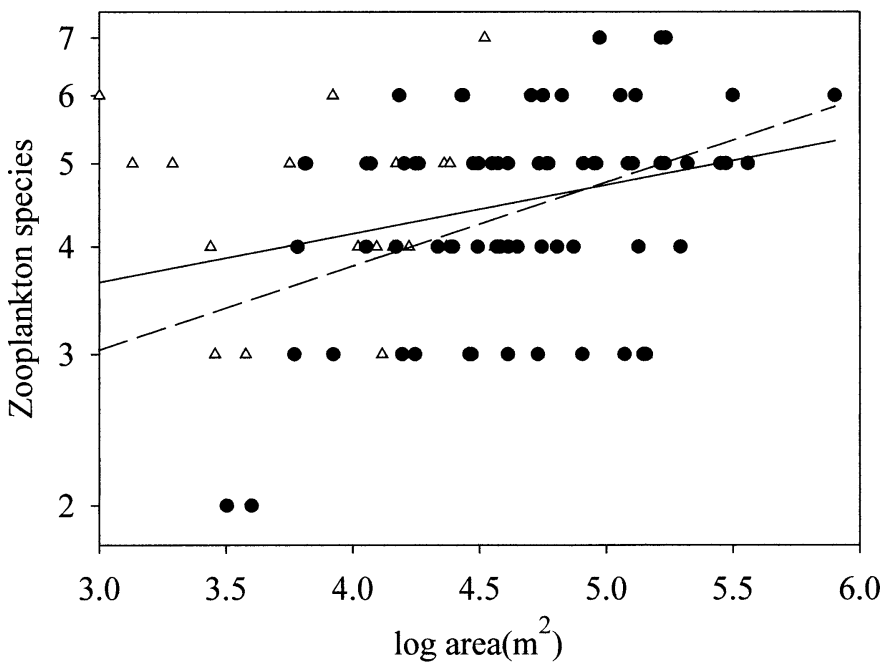

Fig. 3. The species-area curve: the number of zooplankton species in a lake versus the logarithm of lake surface area. Black circles represent lakes with fish; white triangles represent lakes without fish. The solid line is the regression for all lakes (slope $=0.0566$, $\left.r^{2}=0.082, P<0.01\right)$. The dashed line is the regression for lakes with fish only (slope $=0.0975, r^{2}=0.172, P<0.001$ ).

is positively related to the frequency of their occurrence across these arctic lakes.

Zooplankton and lake morphometry-Using logistical regression, $D$. longiremis $(P<0.001$, odds ratio $=1.15), B$. longirostris $(P<0.05$, odds ratio $=1.09)$, and $C$. scutifer $(P<0.05$, odds ratio $=1.46)$ were more likely to be found in deeper lakes, whereas Chaoborus $(P<0.05$, odds ratio $=0.85)$ and megaherbivores $(P<0.01$, odds ratio $=0.58)$ were more likely to be found in shallower lakes that generally lacked fish. The presence of all other zooplankton species was not significantly related to lake depth.

When both lake depth and fish presence were used as predictors, depth was still significant for D. longiremis $(P<$ 0.01 , odds ratio $=1.14), B$. longirostris $(P<0.05$, odds ratio $=1.07)$, and megaherbivores $(P<0.05$, odds ratio $=$ 0.58 ) but was no longer significant for Chaoborus, for which fish presence was significant $(P<0.01$, odds ratio $=10.25)$, and fish were also significant for megaherbivores $(P<0.05$, odds ratio $=21.46)$. Both depth $(P<0.05$, odds ratio $=$ $1.09)$ and the presence of fish $(P=0.001$, odds ratio $=$ 11.66) were significant for $D$. middendorffiana.

Using linear regression, species richness (logarithm of number of species) was significantly related to lake depth and to the logarithm of lake area (both $P<0.01$ ), with higher richness in larger and deeper lakes (Fig. 3, all points and solid line, slope $=0.0566, r^{2}=0.082$ ). It was slightly more significant for depth, but we show the results for area because this is the more commonly reported relationship. This trend was even more pronounced when only lakes with fish were included in the analysis $(P<0.001$; Fig. 3, black symbols and dashed line, slope $=0.0975, r^{2}=0.172$ ).

Zooplankton and lake chemistry-Separate logistical regressions were run for all combinations of the nine species 
Table 1. The relationship between the presence of individual fish species (or any fish) and the presence of zooplankton species.

\begin{tabular}{|c|c|c|c|c|c|c|}
\hline Species & Sculpin & Grayling & $\begin{array}{l}\text { Lake } \\
\text { trout }\end{array}$ & $\begin{array}{l}\text { Arctic } \\
\text { char }\end{array}$ & Whitefish & Any fish \\
\hline B. longirostris & + & 0 & 0 & + & 0 & + \\
\hline D. longiremis & +++ & 0 & + & +++ & 0 & ++ \\
\hline D. pribilofensis & 0 & 0 & 0 & 0 & 0 & 0 \\
\hline C. scutifer & 0 & 0 & 0 & 0 & 0 & 0 \\
\hline H. gibberum & 0 & 0 & 0 & 0 & 0 & 0 \\
\hline D. middendorffiana & 0 & - & 0 & 0 & - & - \\
\hline H. septentrionalis & 0 & 0 & 0 & 0 & 0 & 0 \\
\hline Chaoborus spp. & - & - & - & - & 0 & - \\
\hline Megaherbivores & - & - & - & - & 0 & - \\
\hline
\end{tabular}

0: no significant relationship; $+:$ the zooplankton is more likely when the fish species is present, $-:$ the zooplankton is less likely when the fish species is present. The "Any fish" column gives results of comparing all lakes with fish to lakes without fish.,$+-=P<0.05 ;++,-=P<0.01 ;+++,-=$ $P<0.001$.

of zooplankton and two chemical parameters (conductivity and $\mathrm{Chl} a$ ). Of these 18 analyses, only 3 yielded significant results (all $P<0.001$ ): the presence of $H$. gibberum was negatively related to conductivity (odds ratio $=0.96$ ), and that of $D$. pribilofensis was related positively to conductivity (odds ratio $=1.02$ ) and negatively to chlorophyll (odds ratio $=0.05$ ).

The relationships between zooplankter density and conductivity and chlorophyll were similar (with one additional significant relationship). $H$. gibberum density was negatively correlated with conductivity ( $\gamma$ test, $P<0.001$ ). This was mostly due to the presence of $H$. gibberum only in dilute lakes. When considering only lakes with $H$. gibberum, there was still a somewhat negative relationship between $H$. gibberum density and conductivity, but it was not significant (linear regression on logarithm of densities). Overall, H. gibberum density was positively correlated with $\mathrm{Chl} a(P<$ 0.01). However, considering only lakes with $H$. gibberum, there was no relationship between $H$. gibberum density and Chl $a$ concentration.

D. pribilofensis density was negatively correlated with Chl $a$ and was positively correlated with conductivity (both

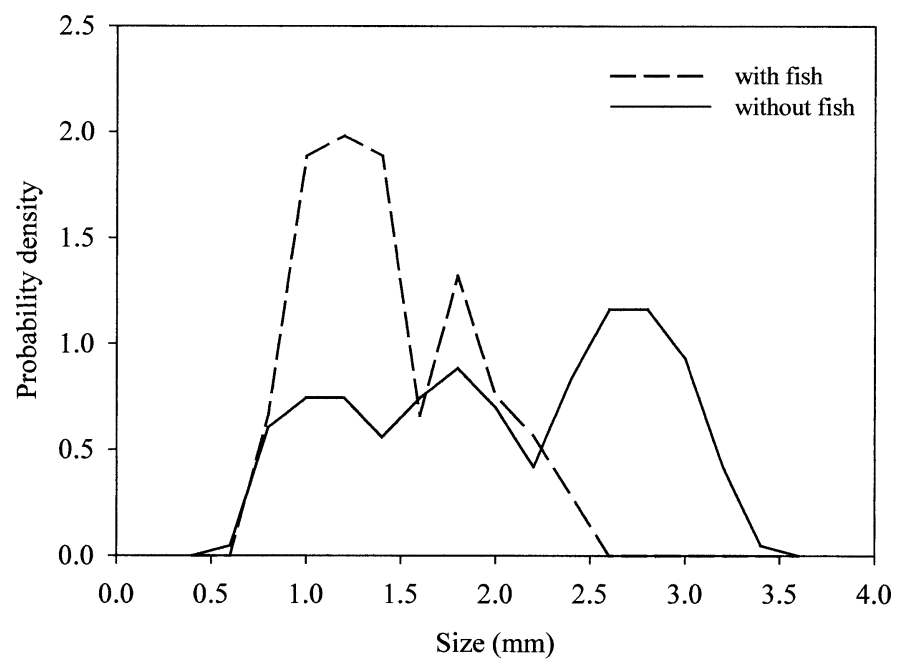

Fig. 4. Size distributions of D. middendorffiana in lakes with and without fish.
$P<0.01$ ), the opposite pattern to $H$. gibberum. The relationship of $D$. pribilofensis density with $\mathrm{Chl} a$ is almost $L$ shaped, with all but one lake with $D$. pribilofensis density $>2 \mathrm{~L}^{-1}$ having Chl $a$ levels $<0.4 \mathrm{mg} \mathrm{L}^{-1}$. In contrast, the relationship with conductivity showed only a higher concentration of points in the low-density, low-conductivity region than elsewhere. Overall, then, it appears that these chemical parameters are relatively unimportant determinants of presence or absence. There was no significant correlation between the density of any other zooplankter and $\mathrm{Chl} a$ or conductivity.

Species richness was not affected by chlorophyll concentration $(P>0.2)$. There was a small and marginally significant negative relationship between species richness and conductivity $(P=0.04$, slope equivalent to $\sim 1$ less species at the highest conductivity, relative to the lowest). However, this effect is entirely due to the presence of $H$. gibberum only in dilute water; if this species is excluded, the slope is slightly positive and $P>0.5$.

Zooplankton and the presence of fish-The presence of zooplankton varied in lakes with and without fish (last column of Table 1). Larger species-D. middendorffiana (in $88 \%$ of lakes without fish and $48 \%$ of lakes with fish), Chaoborus (44\% and $6 \%$ ), and megaherbivores (40\% and $1 \%$ )were more likely to be present in the absence of fish. However, the average size of $D$. middendorffiana was smaller in lakes with fish than in lakes without fish (Fig. 4). Smaller species-D. longiremis (in $49 \%$ of lakes with fish and $16 \%$ without fish) and B. longirostris (49\% and 24\%)-were more likely to be present in lakes with fish.

Table 1 also indicates the significant relationships between the presence or absence of zooplankton species in the lakes and the presence of individual species of fish. Where slimy sculpin or arctic char were present, $B$. longirostris and D. longiremis were more likely to be present and Chaoborus and megaherbivores were less likely to be present. In lakes that contained grayling, D. middendorffiana, Chaoborus, and megaherbivores were less likely to be present. In lakes that contained lake trout, $D$. longiremis was more likely and Chaoborus and megaherbivores were less likely to be present. The presence of $D$. middendorffiana was negatively related to the presence of whitefish. Figure 5 shows the mag- 


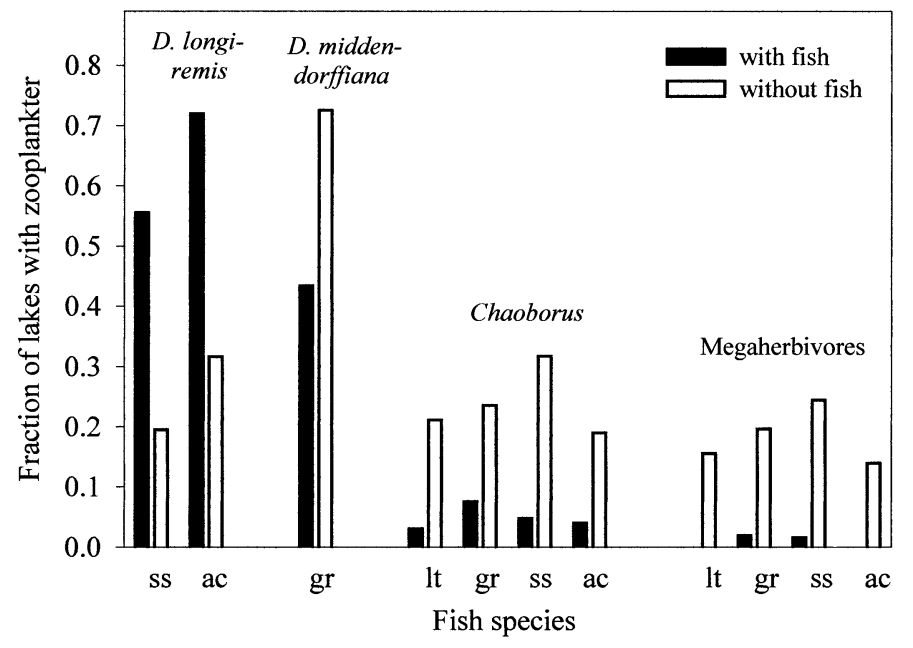

Fig. 5. Highly significant $(P<0.01)$ effects of fish species on the presence of zooplankters. The figure shows the proportion of lakes containing the zooplankter for lakes with and without the fish species. The fish species shown are lake trout (lt), arctic grayling (gr), slimy sculpin (ss), and arctic char (ac).

nitude of the effects (the fraction of lakes with the zooplankter, with and without the fish species) that were significant at the $P \leq 0.01$ level.

The density of all zooplankters except $D$. pribilofensis was significantly related to presence of at least one of fish species (Table 2). In general, higher densities of smaller species of zooplankton and lower densities of larger species occurred in the presence of fish. Some of the patterns of the effects of individual fish species on zooplankton were unexpected. Three species of fish-slimy sculpin, artic char, and lake trout-that are not considered to be highly planktivorous were more consistently related to zooplankton densities than was grayling, which are thought to be more planktivorous than other arctic fish species. Where slimy sculpin or arctic char were present, B. longirostris, D. longiremis, and C. scutifer were more dense; where lake trout was present, $D$. longiremis and $C$. scutifer were more dense. $H$. septentrionalis had lower densities in the presence of sculpin and char, Chaoborus had lower densities with sculpin and lake trout, and megaherbivores had lower densities with sculpin. In the presence of grayling, only one zooplankton species, $H$. gibberum, had increased density, whereas D. middendorffiana, Chaoborus, and megaherbivores tended to have lower densities.

The $G$ test, which examined whether the presence of each zooplankton species was dependent on the fish communities, indicated a significant result for some zooplankters-namely, H. septentrionalis $(P<0.05)$, D. longiremis $(P<0.01)$ and $B$. longirostris $(P<0.01)$. Lakes with only char and sculpin were much less likely to have $H$. septentrionalis and more likely to have $D$. longiremis and $B$. longirostris than any other lakes (although, for $D$. longiremis, three other lake types were close).

Using the Kruskal-Wallis test, there were significant differences by fish community in densities of $C$. scutifer $(P<$ $0.05), H$. septentrionalis $(P<0.05)$, and $D$. middendorffiana $(P=0.001)$. The latter was much more abundant in lakes
Table 2. The relationship between the presence of different species of fish and zooplankton densities.

\begin{tabular}{lcccc}
\hline \hline \multicolumn{1}{c}{ Species } & Sculpin & $\begin{array}{c}\text { Gray- } \\
\text { ling }\end{array}$ & Lake trout & Arctic char \\
\hline B. longirostris & + & 0 & 0 & ++ \\
D. longiremis & +++ & 0 & + & ++ \\
D. pribilofensis & 0 & 0 & 0 & 0 \\
C. scutifer & ++ & 0 & ++ & + \\
H. gibberum & 0 & + & 0 & 0 \\
D. middendorffiana & 0 & - & 0 & 0 \\
H. septentrionalis & - & 0 & 0 & - \\
Chaoborus spp. & - & - & - & 0 \\
Megaherbivores & - & - & 0 & 0 \\
\hline
\end{tabular}

0: no significant relationship; +: higher densities of zooplankton in lakes containing the species of fish; -: lower densities of zooplankton in lakes containing that fish species.,$+-=P<0.05 ;++,-=P<0.01 ;+++$ $=P<0.001$.

with no fish than in any others. Plots of the zooplankton densities by fish community did not indicate any other clear patterns of variation.

There was a significant difference in species richness among the 10 different fish communities $(P<0.05)$. Communities that included char or sculpin alone tended to have high richness $(\geq 5)$, whereas those with no fish or grayling with no char tended to have low richness (as low as 3.6 for lakes with grayling and sculpin only).

Zooplankton and region-Two zooplankton species showed highly significant differences by region $(P<0.001)$. D. pribilofensis was common overall but was present in only $44 \%$ of the lakes in the region northwest of Galbraith Lake. The other species with highly significant results was $H$. gibberum, which was present in none of the lakes in the cluster near Itigaknit Lake (it was present in slightly more than half of all other lakes, including five of nine geomorphic-trophic hypothesis lakes west of the Itigaknit cluster). D. longiremis was also less common in the Itigaknit region, although it was present in $\sim 14 \%$ of these lakes, and the differences with other regions were only significant at the $P=0.05$ level. Only one other zooplankter showed significant $(P<0.05)$ regional differences: $H$. septentrionalis was more common in the Itigaknit cluster and the cluster east of the Kuparuk River and was less common in the other two regions (maximum $77 \%$ around Itigaknit, minimum 33\% northwest of Galbraith Lake).

\section{Discussion}

The zooplankton species found in these lakes are those commonly reported in the Arctic (Edmondson 1955; Comita 1956; O'Brien et al. 1979; Stross et al. 1980; Hobbie 1984). The only exception is Chaoborus. Earlier research that did not report Chaoborus focused on lakes with fish, where Chaoborus almost never occur.

The patterns of co-occurrence we found for zooplankton species are expected and fairly well understood. The presence of two small cladocerans, $D$. longiremis and B. longirostris, was negatively associated with the presence of two 
major zooplanktivorous plankton species $H$. septentrionalis and Chaoborus. Luecke and O'Brien (1983) showed that $H$. septentrionalis ate $>10$ times more small prey than large prey and almost 100 times more of the small-bodied B. longirostris than the large-bodied $D$. middendorffiana. We found $D$. middendorffiana to be positively associated with Chaoborus, likely because the adults of $D$. middendorffiana are essentially immune from Chaoborus predation because of gape limitation in Chaoborus (Swift 1992).

A positive relationship between abundance (geometric mean density where present) and range (occupancy) was observed. This positive relationship has been widely observed, and many explanations have been offered (Holt et al. 1997; Gaston and Blackburn 2000). Two common classes of explanation are based on population (including metapopulation) dynamics and resource use. A third class of explanation is that this relationship is an artifact of sampling; if a species is rare, it is more likely to be missed with inadequate sampling and so might seem to be present in fewer locations. More than three fourths of lakes were $>5 \mathrm{~m}$ deep, and duplicate tows were performed, giving 700-1,400 liters of water sampled for these lakes. With a random zooplankton distribution at a density of $0.005 \mathrm{~L}^{-1}$, we should still detect it $95 \%$ of the time in these lakes. Of course, a few lakes could not be sampled this thoroughly, and zooplankton sometimes have a clumped distribution, so sampling could have an effect, especially for Chaoborus. However, we think this is unlikely to be a significant factor for the megaherbivores, which were almost always observed in the lake by other researchers while they were setting gill nets or searching for sculpin.

Another explanation involves the distribution of fish. The two zooplankton species that we found to be both abundant and widespread (C. scutifer and D. pribilofensis) are much less vulnerable to fish predation than the two that were least abundant and most rare (Chaoborus and the megaherbivores) (Schmidt and O'Brien 1982). The average abundances of the other species, but not their occupancy, were also correlated with their vulnerability to fish predation. In Fig. 2, lakes without fish are indicated with open triangles, and these tend to be lakes with Chaoborus and megaherbivores and with high concentrations of $H$. septentrionalis and $D$. middendorffiana. When we plotted average density versus occupancy for only lakes with no fish, there was no positive relationship but, instead, a $U$-shaped one, with higher densities at low and high occupancies (this is not obvious from the figure, but the occupancies are different if we consider only fishless lakes). This suggests that fish play a role by eliminating some species or reducing them to low levels, allowing others to persist or increase in abundance because of reduced predation or competition.

We also found that $H$. septentrionalis had a lower density than would be expected for its range, compared with other species. Its average value was below the regression line, and, without $H$. septentrionalis, the regression line would be much higher at its occupancy and much closer to linear. This may be because Heterocope is a predator. Predators are frequently less dense than their prey and may occur at fairly low densities even where conditions are quite favorable. With species at different trophic levels, it might be that pred- ators tend to be lower and to the right on density-range plots relative to species at a lower trophic level. However, predators also tend to be larger than their prey, and it has been found that size does not affect the position of a species relative to the regression line (Gaston and Blackburn 2000).

The fish community of the lakes surveyed is quite constrained and consists of only six species. This is due largely to the barrier represented by the Brooks Mountains, which run east to west across the whole northern tier of Alaska and block fish colonization from the south. The fish fauna south of the Brooks Mountains is much more diverse and includes such species as salmon, several species of whitefish, and northern pike (Scott and Crossman 1973; O'Brien and Huggins 1974, 1976). All of the fish species inhabiting the Toolik region ultimately had to have had colonists that invaded the Arctic Ocean and then invaded the streams and rivers draining into the Arctic Ocean.

Although there are only six fish species in the Toolik region, it is clear that they are not randomly assorted across the lakes. Only 17 fish communities (including no fish) occurred of the possible 32 permutations (of the 5 fishes sampled), and 7 of these only occurred in one or two lakes. One reason for this constraint is the morphometry of the landscape, especially the steepness of some critical stretch of the outflow from any given lake. Hershey et al. (1999) showed that the steepness of the outflow of lakes provides a variable barrier that acts as a filter against the invasion of fish species. For example, it is thought that lake trout may be the poorest invader, swimming up only the most gentle of outflow streams (Hershey et al. 1999, 2000). Hence, it would be unusual to find only lake trout in a lake. If lake trout could invade a lake, then a much better invader, such as slimy sculpin, would surely also be present. The survey results show exactly this pattern.

Zooplankton and lake morphometry-The relationships found between the presence of certain zooplankton and lake depth (D. longiremis, B. longirostris, and C. scutifer more likely in deep lakes and Chaoborus sp. more likely in shallow lakes) are probably an effect of fish presence or absence. Fish are more likely to be found in deep lakes, and this is where we found the small zooplankton species that are rarely fed on by fish (O'Brien et al. 1979; Schmidt and O'Brien 1982) but are fed on by large invertebrates. Chaoborus sp. are very vulnerable to fish predation and are therefore found primarily in the shallow lakes, where fish are absent. Except for Chaoborus, depth remained significant (but generally at reduced significance) for all of these zooplankters, even when fish presence was also used as a predictor. So there is some evidence for an effect of depth apart from fish, but, because fish and depth were correlated, the effects of the two were hard to separate, especially with all fish lumped together. (We performed additional analyses using each fish species as a predictor in addition to depth, for which depth was only significant for megaherbivores, but these results were more problematic because of correlations among some fish species.)

The relationship between species richness and lake area is commonly found both for zooplankton (Browne 1981; Fryer 1985; Dodson 1991, 1992), fish (Eckman 1995), and 
many terrestrial island faunal groups (Connor and McCoy 1979). The slopes of the two regression lines in the present study (0.057 all lakes and 0.098 in lakes with fish) were close to those found by Dodson (1991, 1992): 0.054 for 32 European lakes and 0.094 for 64 North American lakes. Most of these lakes probably had fish, so our fish lake regression results are probably the more comparable, and the slope is very similar to that of the North American lakes. However, the variability in arctic lakes is considerably greater than that found by Dodson $(1991,1992)$. Dodson reported $r^{2}=0.33$ for the European lakes and 0.57 for the North American lakes. In comparison, we found $r^{2}=0.082$ for all lakes and 0.172 for lakes with fish. The main reason for our lower $r^{2}$ value is likely the range of the data. Dodson's data sets each spanned $\sim 10$ orders of magnitude in area, whereas our data spanned only 3 . For the same error variance, increasing the range of the independent variable almost always increases $r^{2}$ (because it increases the variance due to the regression). Another possible reason for our lower $r^{2}$ value is the lower number of zooplankton species in our study (a maximum of 7, compared with maxima of 22 in Dodson 1991 and 33 in Dodson 1992). The number of species must be an integer, so, on species-area plots, points must lie on horizontal lines. With a logarithmic species number scale, these lines are farther apart with fewer species. Therefore, there is more error variance because of the discreteness of species number with our data than for those of Dobson. One other possible factor is conductivity, which strongly affects the presence of $H$. gibberum. In fact, the logarithm of conductivity is a significant predictor of the residual of the species-area regression, and including it with area raises $r^{2}$ to 0.31 for lakes with fish.

MacArthur and Wilson (1967) suggested that the speciesarea curve could be explained by differences in immigration and extinction on different-sized islands. We have few data on extinctions but have demonstrated that colonization is still possible, because not all lakes and ponds are inhabited by all of the species that are possible. For example, in 1980 and 1992, H. septentrionalis was introduced into two ponds in the same region that lacked this species, and they thrived (O’Brien and Luecke 1988; O'Brien 2001), which indicates that colonization can still occur in the lakes and ponds of this region.

Zooplankton and lake chemistry-Some of the chemical effects noted here have been observed in other lake regions. It is well known that $H$. gibberum is a species that primarily occurs in lakes of low alkalinity and low calcium (Hamilton 1958; Hessen et al. 1995). Furthermore, other studies have reported that diaptomid and leptodiatomid species tend to be found in lakes with low productivity and phytoplankton biomass (Keller and Pitblado 1984, 1989). However, Keller and Pitelado (1989) found that the major distributional differences of zooplankton species in northern Ontario could not be explained by variations in water quality conditions. Thus, our results showing little effect of lake chemistry on the distribution of zooplankton are consistent with those of others.
Zooplankton and presence of fish-The relationship between the presence or absence of zooplankton species and fish is what might be expected given size-selective feeding by fish (Brooks and Dodson 1965; O'Brien et al. 1990; Walton et al. 1997). The very large bodied zooplankton (megaherbivores and Chaoborus sp.) and the intermediate-sized $D$. middendorffiana are less likely to occur with fish, whereas the small-bodied species $(D$. longiremis and $B$. longirostris) are more likely to occur with fish. The planktivorous feeding of two of the species (lake trout and grayling) have been studied. Schmidt and O'Brien (1982) found that adult and juvenile grayling could locate large zooplankton prey $(2.5 \mathrm{~mm}) 20$ times more readily than small zooplankton (1.0 $\mathrm{mm}$ ), and the prey-locating ability of juvenile lake trout was very comparable (Kettle and O'Brien 1978). The one intermediate body-sized species that did not show a negative relationship with fish was $H$. septentrionalis. Schmidt and O'Brien (1982) found that this species could evade the suction attack of arctic grayling. At $15^{\circ} \mathrm{C}$, adult grayling could not capture $H$. septentrionalis.

Although the relationship between simple fish presence and absence and zooplankton community structure was straightforward, and, as expected, the same was not the case for individual fish species. For example, we did not expect slimy sculpin to have any effect on zooplankton. Yet there was a positive relationship between the presence of sculpin and both $D$. longiremis and B. longirostris, and a negative relationship was seen between sculpin and the very large bodied Chaoborus and megaherbivores. These are the relationships one would expect to find with a major planktivorous fish. Slimy sculpin are a benthic fish that lack an air bladder and are thought to be obligate benthivores (Brandt 1986) and not to occur high up in the water column (Hoekstra and Janssen 1985). Hershey (1985) and Goyke and Hershey (1992) found that sculpin feeding is sufficient to control chironomid densities. However, it may be that the juvenile sculpin are pelagic and feed on zooplankton. We have also captured several sculpin in insect emergence traps positioned several meters off the bottom of lakes. Likewise, the fact that there is a positive relationship between the presence of arctic char and the two small cladocerans, $D$. longiremis and $B$. longirostris, but no such relationship for grayling, is curious. Grayling are thought to be the most highly planktivorous of the six species of fish present in the Toolik region (O'Brien et al. 1979), whereas char feed primarily on snails (A.E.H. pers. obs.).

Fish communities had significant effects on H. septentrionalis, D. longiremis, and B. longirostris. However, no particular fish community stood out as having a dramatic effect on any zooplankton species, with the exception that H. septentrionalis, which was less likely to be present in the char and sculpin community. This result was again unexpected, because neither sculpin nor char are thought to be very planktivorous.

Therefore, there is much evidence for the direct effects of fish on large zooplankton and indirect effects on smaller zooplankton. However, in some respects, the effect of fish is less than might be expected given the results of Brooks and Dodson (1965), who found that large zooplankton could not coexist with a highly planktivorous fish. The comparison to 
Brooks and Dodson (1965) is complex. They dealt with basically two size classes of zooplankton: $0.2-1.0 \mathrm{~mm}$ (small) and $0.6-1.8 \mathrm{~mm}$ (large), with one species, Leptodora (5.0 $\mathrm{mm}$ ), comparable to the megafauna included in the present study. With the introduction of alewives, all of the large zooplankton were eliminated; the only species left was a 0.9 mm Cyclops. In the current study, the small zooplankton $(B$. longirostris, D. longiremis, D. pribilofensis, and C. scutifer) are larger $(0.5-1.8 \mathrm{~mm})$ than the small zooplankton in Crystal Lake. Likewise, the large zooplankton species $(H$. gibberum, D. middendorffiana, and H. septentrionalis) are much larger $(0.5-3.5 \mathrm{~mm})$ than those in Crystal Lake. With the exception of Leptodora, there were no very large zooplankton in Crystal Lake. Yet, even with this, the only nearly absolute effect of fish was that the very large zooplankton rarely exist with fish. After this, there were tendencies for the small cladoceran species $(D$. longiremis and B. longirostris) to occur with fish (possibly because of the elimination of their invertebrate predators by fish) and larger species such as $D$. middendorffiana to occur with fish but with reduced body size. An obvious explanation is that there are no obligate planktivores in the fish fauna in this region. Arctic grayling are known generalists that are able to thrive in both lakes and streams and to forage on a wide variety of prey, from drifting insects in streams to zooplankton and emerging insects in lakes. In the subarctic, where there are whitefish, which are obligate planktivores, the situation is much more like that in Crystal Lake (O'Brien 1975).

We found that the average body size of $D$. middendorffana was smaller in lakes with fish than in lakes without fish (Fig. 4). The median size of the D. middendorffiana in lakes with fish was still larger than the median size of zooplankton found by Brooks and Dodson (1965) in the presence of alewives. Two relatively large zooplankton, $D$. middendorffiana and $H$. septentrionalis, frequently coexisted with fish, including arctic grayling. However, grayling are not particularly planktivorous as adults, as has been shown in diet studies (O'Brien et al. 1979; Merrick et al. 1992). Recent work in a lake in the Toolik region has shown that the summer diet of grayling is composed almost entirely of emerging insects (W.J.O'B. pers. obs.). Furthermore, there is a growing awareness that many fish derive far more energy from benthic sources than has been previously thought (Zanden and Vadeboncoeur 2002).

Zooplankton and region-The striking absence of D. pribilofensis in some of the cluster of lakes to the northwest of Galbraith Lake could be an artifact of the sampling dates, because all the lakes in which this species was absent were sampled during late June (1999). We now have direct evidence that $D$. pribilofensis does not appear in Toolik Lake until early July (Johnson pers. comm.). If these regional lakes are similar, then $D$. pribilofensis could well be present in these lakes, just not in June. The other species that showed a strong regional distribution pattern was $H$. gibberum, which was absent from the lakes near Itigaknit Lake. The surface, and presumably the lakes themselves, are quite young, being deposited during the Itkillik II phase, from 25,000 to 11,500 yr BP (Hamilton 1982). Young landscapes would be expected to have large amounts of solutes, yielding lakes of high conductivity, which is known to inhibit $H$. gibberum. Another species, D. longiremis, was low in occurrence in this same region, whereas $H$. septentrionalis was more common in the region.

Thus, a major finding of the present study was the striking positive relationship between occupancy and density of zooplankton. Two species, D. pribilofensis and C. scutifer, were virtually in every lake and are quite dense, whereas the very large-bodied species were much less dense and occurred only in lakes without fish. The remaining species were intermediate in size, but their distribution across the landscape was complex. Some of these species are responding to lake chemistry like $H$. gibberum or tend to occur together, like $D$. longiremis and B. longirostris. Another major finding was the lack of major effect of any factors other than lake depth and area on species richness (although fish community had some effect). Dodson (1992) found that species richness significantly increased with increasing primary productivity. In the present study, there was no effect of Chl $a$ on species richness. Finally, as discussed above, was the finding of the relatively low effect of fish species on zooplankton distribution. However, the major unusual finding was the effect of arctic char and especially sculpin on zooplankton distribution, which was completely unexpected. Even with the relatively low diversity in these arctic lakes, more research is needed to clarify the interactions between fishes and zooplankton.

\section{References}

BRANDT, S. 1986. Ontogenetic shifts in habitat, diet, and diel-feeding periodicity of Slimy Sculpin in Lake Ontario. Trans. Am. Fish. Soc. 115: 711-715.

BRooks, J. R., AND S. I. Dodson. 1965. Predation, body size, and the composition of the plankton. Science 150: 28-35.

Browne, R. A. 1981. Lakes as islands: The biogeographic distribution, turnover rates, and species composition in the lakes of central New York. J. Biogeogr. 8: 75-83.

Brönmark, C., S. P. KLosiewski, AND R. A. Stein. 1992. Indirect effects of predation in a freshwater food chain. Ecology 73: $1662-1674$.

Carpenter, S. R., J. F. Kitchell, and J. R. Hodgson. 1985. Cascading trophic interactions and lake productivity. Bioscience 35: $634-639$.

- AND OTHERS. 1987. Regulations of lake primary productivity by food web structure. Ecology 68: 1863-1876.

ComitA, G. W. 1956. A study of a calanoid copepod population in an arctic lake. Ecology 37: 576-591.

Connor, E. F., AND E. D. McCoy. 1979. The statistics and biology of the species-area relationship. Am. Nat. 113: 791-833.

Dillon, P. J., N. D. YAn, AND H. H. Harvey. 1984. Acidic deposition: Effects of aquatic ecosystems. Crit. Rev. Environ. Control 13: 167-194.

Dodson, S. I. 1991. Species richness of crustacean zooplankton in European lakes of different sizes. Int. Ver. Theor. Angew. Limnol. Verh. 24: 1223-1229.

1992. Predicting crustacean zooplankton species richness. Limnol. Oceanogr. 37: 848-856

Doka, S. E., M. L. Mallory, D. K. McNicol, and C. K. Mimm. 1997. Species richness and species occurrence of five taxonomic groups in relation to $\mathrm{pH}$ and other lake characteristics in Southeastern Canada. Can. Tech. Rep. Fish. Aquat. Sci. 2179: 62. 
ECKMAN, R. 1995. Fish species richness in lakes of the northeastern lowlands in Germany. Ecol. Freshw. Fish. 4: 62-69.

EDmondson, W. J. 1955. The seasonal life history of Daphnia in an arctic lake. Ecology 36: 439-455.

. 1959. Freshwater biology. Wiley.

Forbes, S. A. 1887. The lake as a microcosm. Bull. Peoria Sci. Assoc. 1887: 1-15.

FRYER, G. 1985. Crustacean diversity in relation to the size of water bodies: Some facts and problems. Freshw. Biol. 15: 347-361.

Gaston, K. J., AND T. M. BlackBurn. 2000. Pattern and process in macroecology. Blackwell Science.

Goyke, A. P., AND A. E. Hershey. 1992. Effects of fish predation on chironomid (Diptera: Chironomidae) communities in an artic ecosystem. Hydrobiologia 240: 203-211.

HAMILTON, J. D. 1958. On the biology of Holopedium gibberum Zaddach (Crustacean: Cladocera). Verh. Int. Ver. Limnol. 13: 785-788.

HAmilton, T. D. 1982. A late Pleistocene glacial chronology for the southern Brooks Range-stratigraphic record and regional significance. Geol. Soc. Am. Bull. 93: 700-716.

. 1986. Late Cenezoic glaciation of Alaska, p. 9-49. In G. Plafker and H. C. Berg [eds.], The geology of Alaska. Geological Society of America.

Hershey, A. E. 1985. Effects of predatory sculpin on the chironomid communities in an arctic lake. Ecology 66: 1131-1138.

$\longrightarrow$, AND OTHERS. 1999. A geomorphic-trophic model for landscape control of arctic lake food webs. Bioscience 49: 887897.

, AND OTHERS. 2000. The geomorphic-trophic hypothesis for arctic lake food webs. Verh. Int. Verein. Limnol. 27: 32693274.

Hessen, D. O., B. A. FaAfeng, And T. Andersen. 1995. Competition or niche segregation between Holopedium and Daphnia empirical light on abiotic key parameters. In P. Larsson and L. J. Weider [eds.], Cladocerans as model organisms in biology. Hydrobiologia 307: 253-261.

HoEkstRa, D., AND J. JANSSEN. 1985. Non-visual feeding behavior of the mottled sculpin, Cottus bairdi, in Lake Michigan. Environ. Biol. Fish. 12: 111-117.

Hobbie, J. E. [ED.]. 1980. Limnology of tundra ponds. Dowden, Hutchinson \& Ross.

2. 1984. Polar limnology, p. 63-104. In F. B. Taub [ed.], Lakes and reservoirs. Elsevier.

Holt, R. D., J. H. Lawton, K. J. Gaston, and T. M. Blackburn. 1997. On the relationship between range size and local abundance: Back to basics. Oikos 78: 183-190.

HrbaceK, J. 1962. Species composition and the amount of zooplankton in relation to the fish stock. Pozpr. Cesk. Akad. Ved. 72: $1-116$.

Hutchinson, G. E. 1967. A treatise on limnology. V. II. Introduction to lake biology and the limnoplankton. Wiley.

Keller, W., AND R. PitBlado. 1984. Crustacean plankton in Northeastern Ontario lakes subjected to acidic deposition. Water Air Soil Pollut. 23: 271-291.

, AND —. 1989. The distribution of crustacean zooplankton in northern Ontario, Canada. J. Biogeogr. 16: 249259.

Kettle, D., AND W. J. O’BRIEN. 1978. Vulnerability of arctic zooplankton species to predation by small lake trout (Salvelinus namaycush). J. Fish. Res. Board Can. 35: 1495-1500.

Lotze, H. K., AND B. Worm. 2001. Strong bottom-up and topdown control of early life stages of macroalgae. Limnol. Oceanogr. 46: 749-757.

Luecke, C., AND W. J. O'BRIEN. 1983. The effect of H. septentrionalis predation on zooplankton communities in arctic ponds. Limnol. Oceanogr. 28: 367-377.
MacArthur, R. H., AND E. O. Wilson. 1967. The theory of island biogeography. Princeton Univ. Press.

McDonald, M. E., B. E. Cuker, And S. C. Mozley. 1982. Distribution, production, and age structure of slimy sculpin in an arctic lake. Environ. Biol. Fish. 7: 171-176.

Merrick, G. W., A. E. Hershey, And M. E. McDonald. 1992. Salmonid diet and distribution, size, and density of invertebrates in an arctic lake. Hydrobiologia 240: 225-247.

Miller, M. C., G. R. Hater, P. Spatt, P. Westlake, and P. YeaKEL. 1986. Primary production and its control in Toolik Lake, Alaska. Arch. Hydrobiol. 74: 97-134.

Northcote, T. G. 1988. Fish in the structure and function of freshwater ecosystems: A "top-down" view. Can. J. Fish. Aquat. Sci. 45: 361-379.

O'Brien, W. J. 1975. Some aspects of the limnology of the ponds and lakes of the Noatak drainage basin, Alsk. Verh. Int. Ver. Limnol. 119: 472-479

- 1979. The predator-prey interaction of planktivorous fish and zooplankton. Am. Sci. 67: 572-581.

- 2001. Long-term impact of an invertebrate predator H. septentrionalis on an arctic pond zooplankton community. Freshw. Biol. 46: 39-45.

- AND OTHERS. 1997. The limnology of Toolik Lake, p. 61106. In A. Milner and M. W. Oswood [eds.], Alaskan freshwaters. Springer.

, H. I. BROWMAN, AND B. I. Evans. 1990. Search strategies of foraging animals. Am. Sci. 78: 152-160.

, C. Buchanan, And J. Haney. 1979. Arctic zooplankton community structure: Exceptions to some general rules. Arctic 32: 237-247.

- AND D. HugGins. 1974. The limnology of the Noatak drainage area, p. 158-223. In S. B. Young [ed.], The environment of the Noatak River basin, Alaska. Contribution from the Center for Northern Studies 1. Center for Northern Studies.

, AND - 1976. A limnological investigation of the lakes and streams of the Charley River area, p. 282-325. In S. B. Young [ed.], The environment of the Yukon-Carley River area, Alaska. Contributions from the Center for Northern Studies, 2. Center for Northern Studies.

, AND C. LUECKE. 1988. The coexistence of a predaceous copepod and a daphnia: Weeding and gardening in the arctic. Verh. Int. Ver. Limnol. 23: 2069-2074.

PAINE, R. T. 1966. Food web complexity and species diversity. Am. Nat. 100: 65-75.

Rawson, D. S. 1952. Mean depth and the fish production of large lakes. Ecology 33: 515-521. . 1955. Morphometry and a dominant factor in the production of large lakes. Verh. Int. Ver. Limnol. 12: 164-174.

Scott, W. B., And E. J. Crossman. 1973. Freshwater fishes of Canada. Bulletin 184. Fisheries Research Board of Canada.

SCHMIDT, D., AND W. J. O'BRIEN. 1982. Planktivorous feeding ecology of arctic grayling (Thymallus arcticus). Can. J. Fish. Aquat. Sci. 39: 475-482.

SHAPIRO, J. 1980. The importance of trophic-level interactions to the abundance and species composition of algae in lakes, $\mathrm{p}$. 105-115. In J. Barica and L. R. Mur [eds.], Hypertrophic ecosystems. Dr. W. Junk.

$\longrightarrow$, AND D. I. WRIGHT. 1984. Lake restoration by biomanipulation. Freshw. Biol. 14: 371-383.

Sokal, R. R., AND F. J. RohlF. 1981. Biometry, 2nd ed. WH Freeman.

Stross, R. G., M. C. Miller, And R. J. Daley. 1980. Zooplankton, p. 251-296. In J. E. Hobbie [ed.], Limnology of tundra ponds. Dowden, Hutchinson, \& Ross.

SwIFT, M. C. 1992. Prey capture by the four larval instars of Chaoborus cystallinus. Limnol. Oceangr. 37: 14-24. 
WAlker, D. A., AND M. D. WALKeR. 1996. Terrain and vegetation of the Imnavait Creek watershed, p. 73-108. In J. F. Reynolds and J. D. Tenhunen [eds.], Landscape function and disturbance in Arctic tundra. Springer.

Walton, W. E., J. A. Miley, And N. G. Hairston Jr. 1997. Effect of prey size on the estimation of behavioral visual resolution of bluegill (Lepomis macrochirus). Can. J. Fish. Aquat. Sci. 54: 2502-2508.

Whalen, S. C., And V. Alexander. 1986. Chemical influences on
$14 \mathrm{C}$ and $15 \mathrm{~N}$ primary production in an arctic lake. Polar Biol. 5: $211-219$.

Zanden, M. J. V., AND Y. Vadeboncoeur. 2002. Fishes as integrators of benthic and pelagic food webs in lakes. Ecology 83: $2152-2161$.

Received: 5 February 2003

Accepted: 17 September 2003

Amended: 29 October 2003 